\title{
Localization of the Angiotensin II and Its Receptor Subtype Expression in Human Endometrium and Identification of a Novel High-affinity Angiotensin II Binding Site
}

\author{
Asif Ahmed, ${ }^{\star \ddagger}$ Xiao F. Li, ${ }^{\star \star}$ Munjiba Shams, ${ }^{\star \ddagger}$ John Gregory, ${ }^{\S}$ Terry Rollason, ${ }^{\S}$ Nicholas M. Barnes," and John R. Newton ${ }^{\ddagger}$ \\ ${ }^{*}$ Reproductive Physiopathology Group, Center for Clinical Research in Immunology and Signalling, ${ }^{\ddagger}$ Departments of Obstetrics and \\ Gynaecology, ${ }^{\S}$ Pathology, "Pharmacology, The Medical School, University of Birmingham, Edgbaston, Birmingham B15 2TT, \\ United Kingdom
}

\begin{abstract}
Angiotensin (ANG) II is not only a potent vasoconstrictor but may also be involved in the regeneration of new blood vessels. In proliferative endometrium, ANG II-like immunoreactivity was detected in glandular epithelium and stroma with negligible staining around the vascular endothelium. In contrast, in secretory endometrium intense immunostaining was seen in the perivascular stromal cells around the endometrial spiral arterioles with negligible staining of the other cell types. Quantitative receptor autoradiography using the nonselective radioligand [ $\left.{ }^{125} I\right]$-ANG II and subtype selective competing compounds showed that endometrium contained predominantly $\mathrm{AT}_{2}$ receptors, with relatively low expression of $\mathrm{AT}_{1}$ receptors and a novel non$\mathrm{AT}_{1} /$ non- $^{-\mathrm{AT}_{2}}$ angiotensin II recognition site that was insensitive to $A T_{1}$ or $A_{2}$ selective ligands. Levels of specific [ $\left.{ }^{125} \mathrm{I}\right]$-ANG II receptor binding displayed cyclic changes during the menstrual cycle, reaching a maximum in early secretory endometrium and then decreasing in mid to late secretory endometrium to levels seen in early to mid proliferative endometrium. In situ hybridization showed $\mathrm{AT}_{1}$ receptor mRNA expression in the glands and in the endometrial blood vessels. The cyclic changes in ANG II-like immunoreactivity together with expression of both the known and the novel AT receptor subtypes imply that this octopeptide may play a dual role both in the control of the uterine vascular bed and also in the regeneration of the endometrium after endometrial shedding, acting as an angiogenic and mitogenic mediator. (J. Clin. Invest. 1995. 96:848-857.) Key words: uterus • autoradiography • in situ hybridization - menstruation • menorrhagia
\end{abstract}

\section{Introduction}

Excessive menstrual bleeding ( $>80 \mathrm{ml}$ ) can lead to iron deficiency anemia and may necessitate hysterectomy. Menorrhagia

\footnotetext{
This work was presented in part at the Society for Gynecologic Investigation Annual Meeting in Chicago on 22-26 March 1994.

Address correspondence to Dr. Asif S. Ahmed, Department of Obstetrics and Gynaecology, University of Birmingham, Birmingham Maternity Hospital, Edgbaston, Birmingham, B15 2TG, United Kingdom. Phone/FAX: 021-627-2705. 1995.

Received for publication 20 June 1994 and in revised form 19 May
}

J. Clin. Invest.

(C) The American Society for Clinical Investigation, Inc.

0021-9738/95/08/0848/10 \$2.00

Volume 96, August 1995, 848-857 can be the result of organic diseases such as polyps, fibroids, pelvic pathology, or carcinoma, but in $>50 \%$ of cases there is neither evidence of underlying pathology nor an imbalance of the hypothalamic-pituitary-ovarian axis. There is increasing evidence to suggest that the mechanisms controlling menstruation and its disorders are regulated by local factors within the endometrium itself (1).

The commencement of menstruation is characterized by intense vasoconstriction of the spiral arterioles (2). After the onset of menstrual bleeding, the upper functional layer of the endometrium is shed, and cessation of bleeding is achieved by vasoconstriction of the remaining basal arteriolar fragments and not by the deposition of platelet-fibrin plugs (3). This vasoconstriction is essential until blood loss is stemmed by the regeneration of the vessels and surrounding tissues (4).

The precise nature of the endometrial vasoconstrictor has not been established. Prostaglandin $\mathrm{F}_{2 \alpha}$ and more recently endothelins have been suggested as possible candidate endometrial vasoconstrictors (5). However, prostaglandin $F_{2 \alpha}$ is usually a relatively weak pressor agent (6). O'Reilly and co-workers (7) reported that there were differences in the ratio of endothelin receptors $\left(E T_{A}\right.$ and $\left.E T_{B}\right)$ receptor $m R N A$ levels in proliferative and secretory endometrium using reverse transcription polymerase chain reaction, but the functional relevance of these changes remains unclear. Although the local factors controlling the uterine vascular bed are poorly understood, it is increasingly clear that they play an important role both in the mechanisms of menstruation and in the preparation of a receptive endometrium for the implantation of the developing embryo.

Historically, angiotensin II (ANG II) ${ }^{1}$ has been associated with the homeostatic regulation of fluid and electrolyte balance and peripheral vascular resistance. More recent studies suggest that it may act as an angiogenic growth factor involved in the regeneration of new blood vessels (8-10). Administration of ANG II to the rabbit cornea (9) or to chick embryo chorioallantois membrane (10) induced pronounced neovascularization and ANG II can be a direct stimulus for cell growth (11). As nonpeptidergic ANG II receptor (AT) antagonists were not effective in blocking the ANG II angiogenesis of pre- and postcapillary vessels (10) definitive proof of this angiogenic effect needs further investigation.

ANG II interacts with specific, high-affinity receptors on the surface of target cells to exert its biological effects. Advances in understanding the structure and function of AT receptors have been facilitated by two recent findings. First, the development of nonpeptide inhibitors of ANG II has clearly established that

1. Abbreviations used in this paper: ANG II, angiotensin II; AT, ANG II receptor. 
there are at least two major classes of AT receptors referred to as $\mathrm{AT}_{1}$ and $\mathrm{AT}_{2}(12)$. Experiments with the $\mathrm{AT}_{1}$-specific inhibitor losartan (previously designated DuP753) indicate that this subtype is responsible for at least the vast majority of the hemodynamic and cardiovascular effects of ANG II (12). Second, several groups have used molecular techniques to isolate cDNA encoding $\mathrm{AT}_{1}$ (13) and $\mathrm{AT}_{2}$ receptors (14). The $\mathrm{AT}_{1}$ receptor is sensitive to nanomolar concentrations of losartan $(1,000$ fold selectivity over $\mathrm{AT}_{2}$ receptor) and is a $\mathrm{G}$ protein-coupled receptor which activates a signal transduction mechanism involving phosphoinositide hydrolysis and $\mathrm{Ca}^{2+}$ mobilization (15). In contrast, the $\mathrm{AT}_{2}$ receptor is sensitive to nanomolar concentrations of PD123177 (1,000-fold selectivity over $\mathrm{AT}_{1}$. receptor) and does not appear to be coupled to a transduction system via a $G$ protein but may promote cell growth (16). ANG II may be a crucial local factor in the endometrium since intense vasoconstriction of the spiral arterioles is a prerequisite for normal menstruation and the microvascular system responds with rapid capillary growth associated with endometrial regeneration after menstruation. Mapping of the tissue distribution of $\mathrm{AT}$ receptors is therefore essential for a understanding of the role of ANG II in this tissue.

\section{Methods}

\section{Tissue collection}

Endometrium was collected from women undergoing dilatation and curettage for laporascopic sterilization. Tissues were obtained from 28 women for immunocytochemical studies, from 27 women for quantitative receptor autoradiographic studies, and from 8 women for in situ hybridization studies. Patients selected had no apparent endocrinological problems and no local organic pathologies. All tissues were obtained from 20-40-yr-old women with a history of regular menstrual cycles. None of the patients has taken any hormonal medication for at least 3 mo before surgery. Specimens of endometrium were obtained from proliferative and secretory phases of the cycle and the day of the cycle was confirmed by independent histological assessment $(17,18)$. Ethical committee approval was obtained from the South Birmingham Ethical Committee.

The tissue was rinsed in sterile saline and immediately immersed in $10 \%$ formaldehyde and routinely processed for paraffin wax embedding. Tissue was also rapidly frozen over dry-ice, wrapped in Parafilm to prevent dehydration, and stored at $-80^{\circ} \mathrm{C}$ until they were sectioned for receptor autoradiographic or in situ hybridization studies. Frozen endometrium and myometrial tissues were surrounded in embedding medium (Tissue-Teck O.C.T. Compound; Agag Scientific, Stanstead, Essex, United Kingdom) before $20-\mu \mathrm{m}$ sections were cut using a cryostat $\left(-15\right.$ to $\left.-19^{\circ} \mathrm{C}\right)$ and thaw mounted onto gelatin-coated glass slides for receptor autoradiographic studies, and $10-\mu \mathrm{m}$ sections were cut and thaw mounted onto poly-L-lysine (Sigma Chemical Co. Ltd., Poole, United Kingdom) coated glass slides for in situ hybridization studies. Sections were stored $(<2 \mathrm{wk})$ and desiccated at $-80^{\circ} \mathrm{C}$ until used.

\section{Immunocytochemistry}

Serial 3- $\mu \mathrm{m}$ sections of formalin-fixed, paraffin-embedded tissue were used for immunohistochemistry as previously reported (19). Sections were deparaffinized by incubation for $5 \mathrm{~min}$ with histoclear and hydrated through methanol to water. Endogenous peroxidase activity was quenched by $0.3 \%$ ( $\mathrm{vol} / \mathrm{vol}$ ) hydrogen peroxide in methanol for 10 min. The primary antibody was a rabbit polyclonal antibody raised against the human ANG II and was purchased from Peninsula Laboratories (Merseyside, United Kingdom). It is highly specific but crossreacts completely with human ANG III and very slightly with angioten$\sin I(0.5 \%)$ and renin $(1 \%)$. Nonimmune goat serum ( $10 \%$ in 0.01 mol/liter PBS, pH 7.2) was used as a dilution of the primary antibody to reduce nonspecific binding. Amplification of the primary antibody reaction was achieved using a goat anti-rabbit secondary antibody (diluted 1:200 in $0.01 \mathrm{~mol} /$ liter PBS, pH 7.2) for $30 \mathrm{~min}$ followed by a complex of streptavidin and biotinylated peroxidase (both from Dako Ltd., Bucks, United Kingdom). Finally, the binding was visualized by the addition of $0.5 \mathrm{mg} / \mathrm{ml}$ diaminobenzidine (Sigma Chemical Co. Ltd.) and $0.01 \%$ hydrogen peroxide in $0.01 \mathrm{mmol} /$ liter PBS to the antigenantibody complex. Between each step the sections were washed in 3 $\times 200 \mathrm{ml}$ of $0.1 \%$ ( $\mathrm{vol} / \mathrm{vol}$ ) polyoxylene-10-oleoyl-ether in $0.01 \mathrm{mmol} /$ liter PBS, pH 7.2, over a period of $15 \mathrm{~min}$. All incubations of antisera were carried out at room temperature in a wet chamber mounted on a rocking tray which ensures a movement of antiserum over the whole section. The sections were counterstained with Mayer's hematoxylin, dehydrated, and mounted.

To test the specificity of the immunocytochemical staining, the primary antibody was omitted from the sections or replaced with goat nonimmune serum in control experiments. Controls were also performed by preabsorbing the primary antibody with ANG II at a concentration of $16.6 \mu \mathrm{l}$ antibody/mg ANG II for $24 \mathrm{~h}$ at $4^{\circ} \mathrm{C}$. Finally, as ANG II is known to be present in blood products and endometrial biopsies may be contaminated by blood products as well as the procedure being traumatic, endometrium was also obtained from hysterectomy specimens as control.

Evaluation of immunostaining. An arbitrary four point scale was used to grade the intensity and the proportion of positively stained cells. A score of four indicated very intense staining of $>95 \%$ for stromal cells, glandular epithelium, and blood vessels compared with a score of zero which indicates an absence of staining. A score of one to three indicated occasional, very weak, and moderate intensity of staining, respectively. Both the immunohistochemistry and the scoring of positively stained cells were performed by a single individual without prior knowledge of the phase of the menstrual cycle.

\section{[ ${ }^{125}$ I]-ANG II autoradiography}

Three endometrial sections were mounted on the same slide from each patient sample. Slide-mounted human endometrial sections were removed from storage and allowed $\sim 30 \mathrm{~min}$ to equilibrate to room temperature. To reduce endogenous levels of ANG II in the tissue, the sections were preincubated for $60 \mathrm{~min}$ in incubation buffer $(\mathrm{mM})$ : sodium chloride, 150; sodium dihydrogen phosphate, 50; magnesium chloride, 10; ethyleneglycol-bis-( $\beta$-amino-ethyl ether) $N, N^{\prime}$-tetra-acetic acid, 5; and $0.4 \% \mathrm{wt} / \mathrm{vol}$ bovine serum albumin, $\mathrm{pH} 7.4$ ) at $25^{\circ} \mathrm{C}$. The slides were then incubated in incubation buffer which contained $0.1 \mathrm{nM}$ Iodotyrosyl ${ }^{125}$ I-[ 5-L-isoleucine]-ANG II ( ${ }^{125} \mathrm{I}-\mathrm{ANG}$ II, $2000 \mathrm{Ci} / \mathrm{mmol}$; Amersham International, Bucks, United Kingdom) in the absence (total binding) or presence of competing compound (either $1.0 \mu \mathrm{M}$ unlabeled ANG II, $1.0 \mu \mathrm{M}$ DuP753, $1.0 \mu \mathrm{M}$ PD123177, or $1.0 \mu \mathrm{M}$ DuP753 plus $1.0 \mu \mathrm{M}$ PD123177) for $60 \mathrm{~min}$ at $25^{\circ} \mathrm{C}$. Immediately after incubation, the tissue sections were washed in ice-cold incubation buffer for $2 \mathrm{~min}$ and dipped $(1 \mathrm{~s})$ in ice-cold distilled water to remove buffer salts. The sections were rapidly dried in a stream of cold dry air and exposed to Hyperfilm- $\left[{ }^{3} \mathrm{H}\right]$ (Amersham International) in $\mathrm{x}$-ray cassettes together with [ $\left.{ }^{125} \mathrm{I}\right]$ standards (Amersham International) for $40 \mathrm{~d}$. Autoradiographic films were developed in Kodak LX 24 developer ( $5 \mathrm{~min}$ ) and Kodak Unifix ( $5 \mathrm{~min}$ ).

Evaluation of autoradiography. After the development of autoradiographic film, the silver grain density was assessed using image analysis (MCID; Imaging Research Inc., St. Catherines, Ontario, Canada) from the three sections on each slide and a mean value was generated which represented $n=1$. The film was quantified by reference to [ $\left.{ }^{125} \mathrm{I}\right]-$ standards (femtomoles per milligram of tissue equivalent values for intact grey matter; Amersham International). Unpaired Student's $t$ test or ANOVA test followed by Dunnett's test, where appropriate, was applied to compare the changes in the mean values of silver grain density at different stages of cycle in the groups.

\section{In situ hybridization}

A 45-bp-long synthetic oligonucleotide probe complementary to the bases 1821-1866 of the rat $\mathrm{AT}$ type $1 \mathrm{~A}\left(\mathrm{AT}_{1 \mathrm{~A}}\right)$ receptor was synthe- 
sized and used to locate the mRNA that encode the receptor protein (20). This region of the $\mathrm{AT}_{1 \mathrm{~A}}$ gene was chosen because it was found to be divergent from other homologous genes. It was found to be mismatched by three base pairs to the corresponding human $\mathrm{AT}_{1}$ gene (21). The incubation conditions and washing temperatures were adjusted accordingly. The oligoprobe was end labeled with [ $\left.{ }^{35} \mathrm{~S}-\mathrm{dATP}\right]$ by terminal transferase using a commercially available kit (both from Du Pont, Stevenage, United Kingdom). The specificity of the oligonucleotides was checked by ensuring that the probe hybridized to the correct transcript in poly (A) ${ }^{+}$RNA isolated from the endometrium under study on a Northern blot.

In situ hybridization was performed as previously reported (22). Endometrial and myometrial sections were prepared on poly-L-lysinecoated slides and fixed in 4\% paraformaldehyde in PBS ( $\mathrm{pH} 7.4$ ) for $5 \mathrm{~min}$, acetylated in $0.1 \mathrm{M}$ triethanolamine (TEA), $\mathrm{pH} 8.0$, with acetic anhydride $(0.25 \% \mathrm{wt} / \mathrm{vol})$ for $10 \mathrm{~min}$. Slides were dehydrated through an ascending graded series of alcohol $(70,80,95$, and $100 \% \mathrm{vol} / \mathrm{vol})$ followed by incubation in chloroform for $5 \mathrm{~min}$. The sections were then partially rehydrated sequentially in $100 \%$ ( vol/vol) and $95 \%$ ( vol/vol) ethanol and air dried. As a control for nonspecific binding, before fixation, some sections were treated with $100 \mu \mathrm{g} / \mathrm{ml}$ of RNAse A (Sigma Chemical Co. Ltd.) for $1 \mathrm{~h}$ at $37^{\circ} \mathrm{C}$.

After acetylation, the air-dried slides were hybridized in a moist chamber under coverslips in the hybridization buffer containing formamide ( $50 \% \mathrm{vol} / \mathrm{vol}$ ), $3 \mathrm{M} \mathrm{NaCl}, 0.3 \mathrm{M}$ sodium citrate, $01 \mathrm{mM}$ EDTA, dextran sulfate ( $10 \% \mathrm{wt} / \mathrm{vol}$ ), $0.5 \mathrm{ml}$ Denhardt's reagent, 100 $\mu \mathrm{g} / \mathrm{ml}$ of salmon sperm DNA, $100 \mu \mathrm{g} / \mathrm{ml}$ of yeast transfer RNA, 100 $\mu \mathrm{g} / \mathrm{ml}$ of polyadenylic acid $\mathrm{A}$, and $1 \times 10^{6} \mathrm{cpm} / \mathrm{ml}$ of ${ }^{35} \mathrm{~S}$-labeled antisense oligoprobe. Hybridization was carried out at $27^{\circ} \mathrm{C}$ for $16 \mathrm{~h}$. Control hybridization was performed using radiolabeled antisense oligoprobe in the presence of 100 -fold excess of unlabeled antisense strand. After hybridization, the coverslips were removed and the slides were then washed four times in $1 \times$ SSC for $25 \mathrm{~min}$ at a wash temperature of $56.5^{\circ} \mathrm{C}$. The slides were then further washed twice in $1 \times$ SSC at room temperature and air dried. Autoradiography was carried out by coating the slides in Ilford K5 emulsion (Ilford Ltd., Cheshire, United Kingdom) at $4^{\circ} \mathrm{C}$ for $5 \mathrm{wk}$. The sections were then stained lightly with $0.1 \%$ cresyl violet and mounted.

\section{Results}

\section{Immunocytochemical localization of ANG II}

ANG II-like immunoreactivity was detected in endometrium through the menstrual cycle. There was a marked difference in the pattern of staining between different phases of the menstrual cycle. The positive control of rat adrenal sections showed intense positive staining. Staining was localized in the glandular epithelium and the stroma in the proliferative phase of the menstrual cycle, with negligible staining around the vascular endothelium (Fig. 1, $A$ and $B$ ). In contrast, the staining intensified around the blood vessels of the endometrium in the secretory phase (Fig. 1, C-F). The cyclic changes in the pattern of staining in the stroma, glands, and blood vessels through the menstrual cycle are graphically illustrated according to an arbitrary grading system (Fig. 2). No difference in the staining pattern was seen in sections of endometrium obtained by D \& C or hysterectomy. No specific staining was seen when preimmune serum was substituted and staining was attenuated in control sections in which primary antibody was preincubated with the peptide.

During the early proliferative phase, heterogeneous staining was found in the stroma and the glandular epithelium and the degree of staining varied from very weak to intense. Some of the stromal and glandular cells showed the intense typical brown granular cytoplasmic staining and no staining was seen around the endometrial blood vessels (Fig. 1, $A$ and $B$ ). In the mid proliferative phase, the immunoreactivity was noted in some of the cells in the stroma and in the glandular epithelium. These cell types showed relatively weak to moderate staining during the mid proliferative phase and the intensity of staining appeared to decrease compared with the earlier phase of the cycle. Again, no positive staining was seen around the endometrial blood vessels. During the late proliferative phase negligible immunoreactivity to ANG II was observed in the stroma, the glands, and the blood vessels.

In contrast, positive staining was localized around the endometrial spiral arterioles during early secretory phase with negligible staining in glandular epithelium and stroma (Fig. 1, C and $D$ ). There was an increase in the intensity of staining which was diffused around endometrial blood vessels during the mid secretory phase with minimal or entirely absent staining in the stroma. Moderate staining in the glands was observed in some cases. During the late secretory phase the intensity of staining was visually enhanced and localized in the perivascular stromal cells around the endometrial blood vessels (Fig. 1, $E$ and $F$ ). The glandular epithelium showed weak staining and the stroma appeared relatively negative to the primary antibody in the late secretory phase of the cycle (Fig. 1, $E$ and $F$ ).

\section{[ ${ }^{125}$ I]-ANG II autoradiography}

Levels of AT receptor subtypes in 27 endometrial specimen from women (mean age $35.3 \mathrm{yr}$, range 18-39 yr) with normal cyclic menstruation were quantified as described in Methods. Of the 27 endometrial specimens, histological assessment of the specimens resulted in the following classifications: 1 was early proliferative, 4 were mid proliferative, 7 were late proliferative, 3 were early secretory, 6 were mid secretory, and 6 were late secretory.

Adjacent sections incubated with [ $\left.{ }^{125} I\right]-A N G$ II labeled a saturable binding site in human endometrial-myometrial sections (Fig. 3). Specific binding (defined by the inclusion of unlabeled ANG II, $1.0 \mu \mathrm{M}$ ) was mainly associated with the $\mathrm{AT}_{2}$ receptor since it was sensitive to the inclusion of PD123177 (Fig. $3 C$ ). Within the endometrium, the $\mathrm{AT}_{2}$ receptor specific ligand competed for mean ( \pm SEM) $65 \pm 4.3 \%$ of the total binding. In contrast, the specific losartan-sensitive binding represented only $19 \pm 4.7 \%$ of the total binding. In addition to losartan- and PD123177-sensitive specific [ $\left.{ }^{125} \mathrm{I}\right]$-ANG II, an additional specific site was consistently detected that was insensitive to both losartan $(1 \mu \mathrm{M})$ and PD $123177(1 \mu \mathrm{M})$ (Fig. $3 D)$ but sensitive to $1 \mu \mathrm{M}$ unlabeled ANG II (Fig. $3 E$ ). This novel high-affinity AT recognition site represented $\sim 16 \pm 3.6 \%$ of specific binding of the total binding.

$A T$ receptor binding levels. The mean ( \pm SEM) levels of specific $\left[{ }^{125} \mathrm{I}\right] \mathrm{AT}$ receptor binding for $\mathrm{AT}_{1}$ and $\mathrm{AT}_{2}$ receptors showed cyclic variation. Although they paralleled each other, the levels of $\mathrm{AT}_{2}$ receptor were significantly higher than $\mathrm{AT}_{1}$ receptor throughout the cycle. The mean levels of $\mathrm{AT}_{1}$ and $\mathrm{AT}_{2}$ receptor specific binding increased from the early and mid proliferative endometrium to the late proliferative endometrium (Fig. 4, $A$ and $B$ ). Both, $\mathrm{AT}_{1}$ and $\mathrm{AT}_{2}$ receptor levels were maximal in the early secretory endometrium and then decreased in the mid and late secretory endometrium. The mean levels of $\mathrm{AT}_{1}$ receptor specific binding in the early secretory phase was $0.182 \pm 0.040 \mathrm{fmol} / \mathrm{mg}$ tissue equivalent and this was significantly higher than those in the mid proliferative $(0.034 \pm 0.021$ $\mathrm{fmol} / \mathrm{mg}$ tissue equivalent; $P<0.05$ ) or mid secretory 

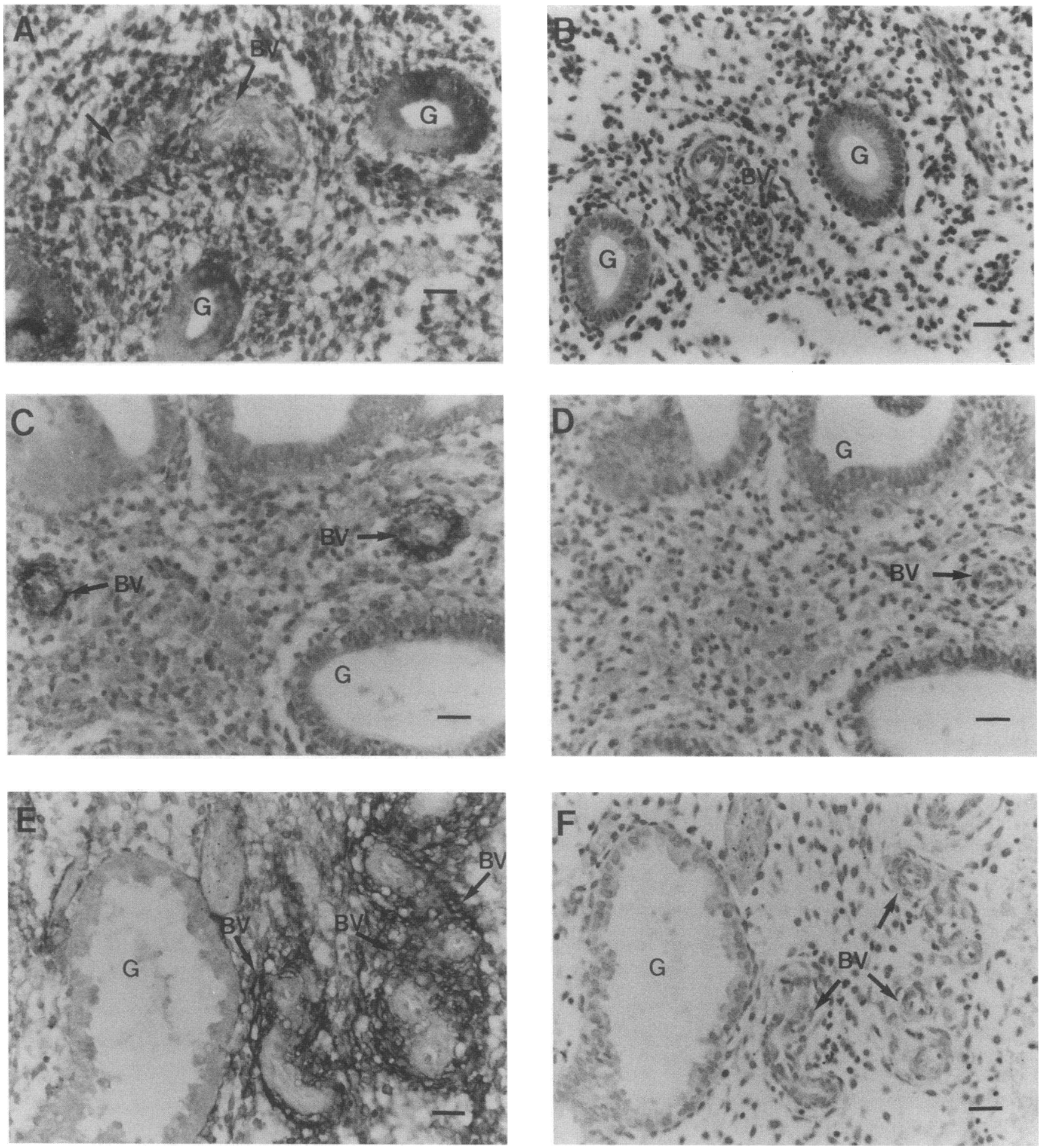

Figure 1. ANG II-like immunoreactivity in endometrium. Serial sections of endometrium from early proliferative $(A$ and $B)$, early secretory $(C$ and $D)$, and late secretory $(E$ and $F)$ phases were incubated with primary antibody $(A, C$, and $E)$ or with nonimmune serum $(B, D$, and $F)$. Staining is seen in the glands $(G)$ and stromal cells and no staining is observed around the blood vessels $(B V)$ as indicated by the arrows. Bar, $40 \mu \mathrm{m}$.

$(0.048 \pm 0.022 \mathrm{fmol} / \mathrm{mg}$ tissue equivalent; $P<0.05)$ and late secretory endometrium $(0.051 \pm 0.020 \mathrm{fmol} / \mathrm{mg}$ tissue equivalent; $P<0.05$ ). Similarly, the mean levels of $\mathrm{AT}_{2}$ receptor specific binding in the early secretory endometrium was $0.421 \pm 0.053 \mathrm{fmol} / \mathrm{mg}$ tissue equivalent and this too was significantly higher than those in the mid proliferative $(0.099 \pm 0.032 \mathrm{fmol} / \mathrm{mg}$ tissue equivalent; $P<0.01)$ or $\mathrm{mid}$ secretory $(0.062 \pm 0.024 \mathrm{fmol} / \mathrm{mg}$ tissue equivalent; $P<0.001)$ and late secretory endometrium $(0.115 \pm 0.079 \mathrm{fmol} / \mathrm{mg}$ tissue equivalent; $P<0.05$ ). There were no significant differences 

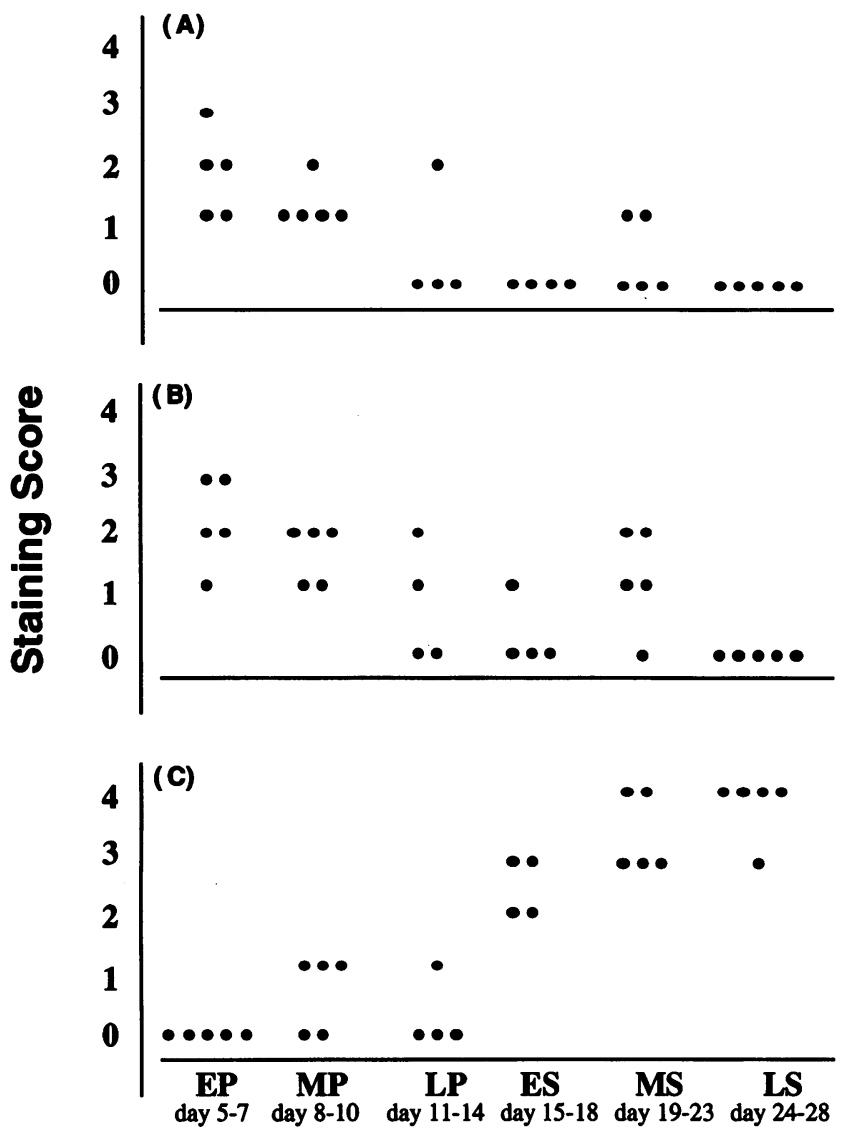

\section{Menstrual cycle}

Figure 2. Graphical representation of the cyclic changes in the cellular distribution of immunostaining during the menstrual cycles. Immunohistological staining scores in the stroma $(A)$, the glands $(B)$, and around the vessels $(C)$ in individual samples (solid circles) of the endometrium during the menstrual cycles. The degree of change in intensity and numbers of cells staining were graded according to an arbitrary four point scale. A score of four indicates intense staining of $>95 \%$ of the glands, stroma cells, and vessels compared with a score of one which indicates occasional or very weak staining, and score of zero means negative. $E P$, early proliferative; $M P$, mid proliferative; $L P$, late proliferative; $E S$, early secretory; $M S$, mid secretory; $L S$, late secretory.

in the levels of $\mathrm{AT}_{1}$ and $\mathrm{AT}_{2}$ receptor specific binding between the late proliferative and early secretory endometrium. The levels of non- $\mathrm{AT}_{1} /$ non- $\mathrm{AT}_{2}$ receptor specific binding in endometrium were very low throughout the menstrual cycle and did not change significantly during the menstrual cycle (Fig. $4 \mathrm{C}$ ).

\section{In situ hybridization for $A T_{1}$ mRNA}

In situ hybridization was performed to identify the site of expression of $\mathrm{AT}_{1}$ receptor mRNA in endometrium. In the proliferative endometrium, the level of the hybridization signal was distributed over both the glandular epithelium and stroma (Fig. $5, A$ and $B$ ). The intensity of hybridization decreased in the stromal cells in the secretory endometrium (Fig. 5, $C$ and $D$ ), however $\mathrm{AT}_{1}$ receptor mRNA signal was maintained in the endometrial glands (Fig. 5, $C$ and $D$ ). Endometrial blood vessels showed intense expression for $\mathrm{AT}_{1}$ receptor mRNA and in situ hybridization signals were higher around the blood vessels
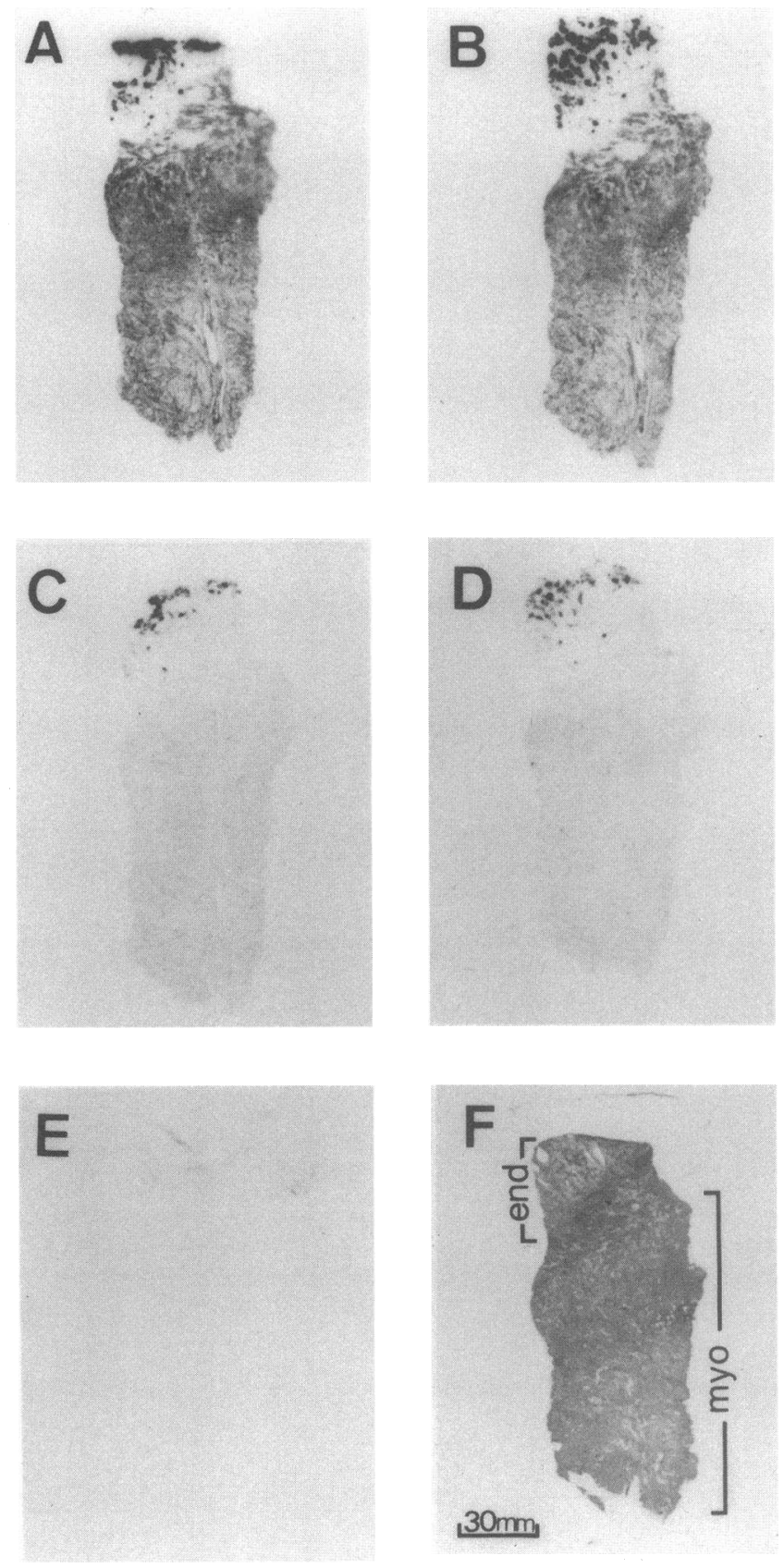

Figure 3. Autoradiograms of the distribution of $\left[{ }^{125} \mathrm{I}\right]-\mathrm{ANG}$ II binding to adjacent sections of the human endometrium. Dark regions indicate high densities of labeled receptors. $A$, total binding; $B$, binding in the presence of the $\mathrm{AT}_{1}$ receptor selective ligand DuP753 $(1.0 \mu \mathrm{M}) ; C$, binding in the presence of the $\mathrm{AT}_{2}$ receptor selective ligand PD123177 $(1.0 \mu \mathrm{M}) ; D$, binding in the presence of DuP753 $(1.0 \mu \mathrm{M})$ plus PD123177 $(1.0 \mu \mathrm{M}) ; E$, binding in the presence of unlabeled ANG II $(1 \mu \mathrm{M})$. Nota bene: the difference in density between A and B represents $\mathrm{AT}_{1}$ receptor specific binding; difference in density between $\mathrm{A}$ and $\mathrm{C}$ represents $\mathrm{AT}_{2}$ receptor specific binding; difference between $\mathrm{A}$ and $\mathrm{D}$ represents specific $\mathrm{AT}_{1}$ plus $\mathrm{AT}_{2}$ receptor density, and the difference between $\mathrm{D}$ and $\mathrm{E}$ represents the non- $\mathrm{AT}_{1} /$ non- $\mathrm{AT}_{2}$ novel $\mathrm{AT}$ recognition site. Bar, $30 \mathrm{~mm}$.

compared with the surrounding tissue. The signal was expressed in the arteriolar smooth muscle, which is not surprising as vascular smooth muscle is a critical target organ for ANG II. There 

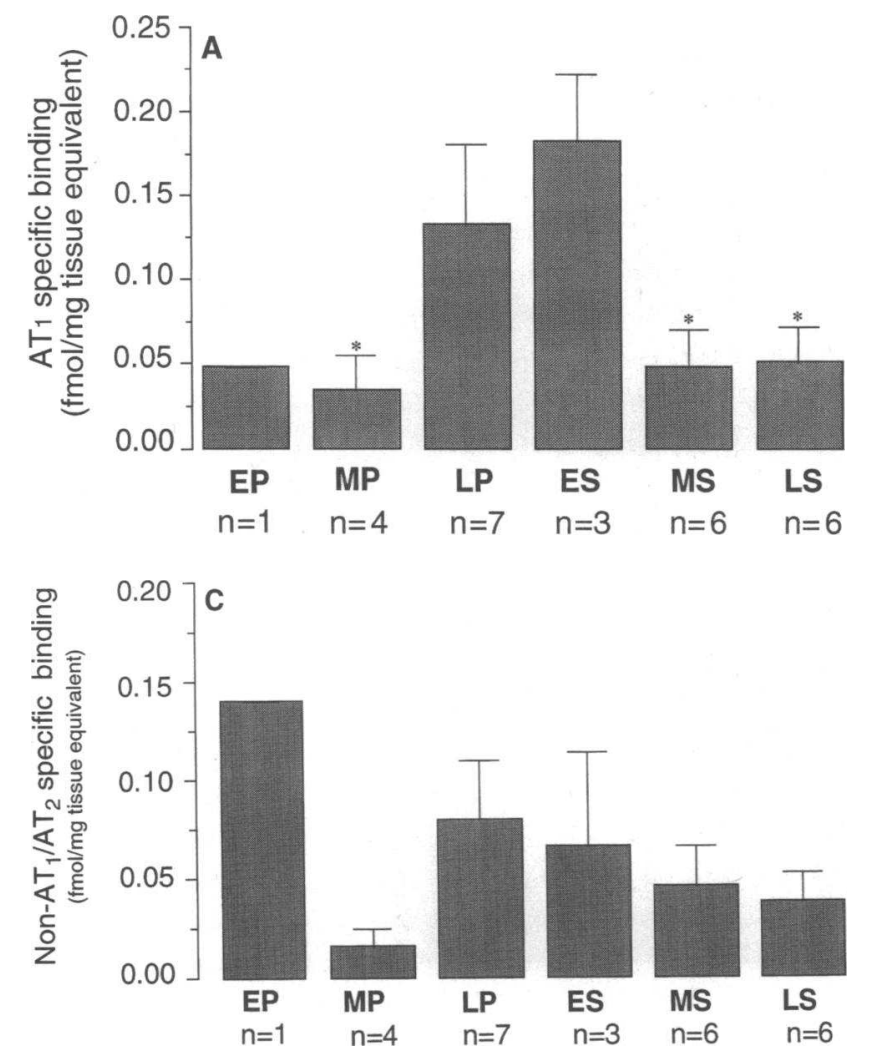

was negligible hybridization signal in RNAse pretreated sections (Fig. 5, $E$ and $F$ ). The specificity of the signal was further confirmed by incubating labeled probe along with 100 -fold excess of unlabeled probe, which demonstrated that the hybridization signal was significantly lower compared with hybridization induced by the labeled probe alone (Fig. 5, $G$ and $H$ ). Intense hybridization signal was seen in the basalis region of the endometrium (Fig. 6, $A$ and $C$ ) in and around the blood vessels. Low levels of expression of $\mathrm{AT}_{1}$ receptor mRNA were also seen in the myometrium with strong hybridization signal in isolated cells (Fig. 6, $B$ and $D$ ).

\section{Discussion}

There is increasing evidence in many tissues, including human ovaries (23) and human endometrium (24), to suggest the existence of locally active tissue renin-angiotensin systems (25). A recent study showed that the stromal cells of human endometrium are capable of synthesizing a renin-like substance. Renin production was significantly increased by progesterone and the maximum potential to produce the angiotensin coincided with the triggering events of menstruation $(24,26)$, indicating a potential function in the control of menstruation. The present study clearly demonstrates that ANG II-like immunoreactivity in human endometrium undergoes cyclic changes throughout the menstrual cycle. Although immunocytochemical technique is not able to differentiate between the sites of synthesis of ANG II and ANG II bound to its receptors, the intense cytoplasmic immunostaining suggests that the immunoreactivity is largely due to endogenous levels of ANG II within the cells. Support for local renin-angiotensin system is also provided by the findings of Raju and Lee (27) showing the presence of immunoreac-

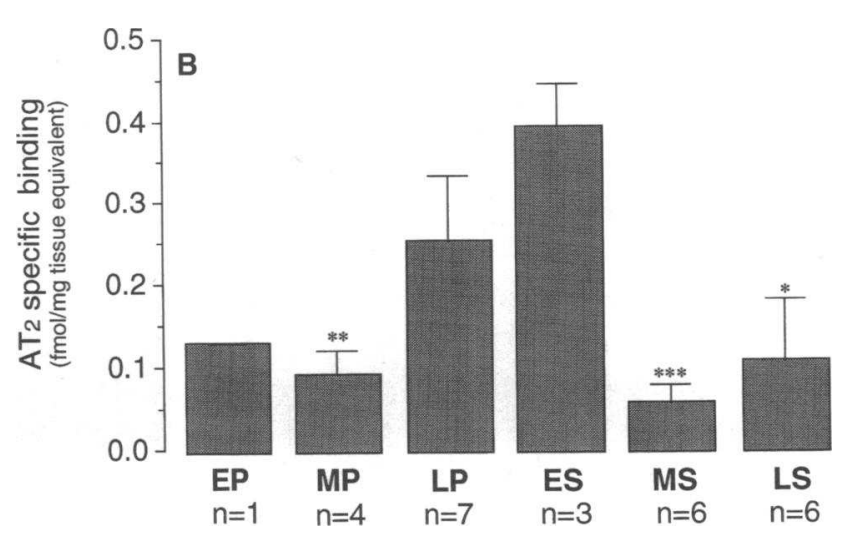

Figure 4. The levels of specific $\left[{ }^{125} \mathrm{I}\right]-\mathrm{ANG}$ II binding sites in endometrium throughout the menstrual cycles. Data represent the mean ( \pm SEM) of $\mathrm{AT}_{1}(A), \mathrm{AT}_{2}(B)$, and non- $\mathrm{AT}_{1} /$ non- $\mathrm{AT}_{2}(C)$ specific binding in endometrial specimens from women with normal menstrual cycles. Significantly higher levels of $\mathrm{AT}_{1}$ and $\mathrm{AT}_{2}$ specific binding in the early secretory phase endometrium were detected compared with those in the endometria of the mid proliferative, mid secretory, and late secretory phase. There was no significant difference in the $\mathrm{AT}_{1}$ or $\mathrm{AT}_{2}$ specific binding levels between the early secretory and late proliferative. $E P$, early proliferative; $M P$, mid proliferative; $L P$, late proliferative; $E S$, early secretory; $M S$, mid secretory; $L S$, late secretory. ${ }^{*} P<0.05 ;{ }^{*} P<0.01$; $* * * P<0.001$ (one-way ANOVA followed by Dunnett's $t$ test, compared with the level in the early secretory endometrium).

tive renin in endometrial cells, the enzyme responsible for the conversion of ANG to ANG I. However, immunostaining due to ANG II bound to receptors cannot be ruled out.

In this study, staining was localized in the glandular epithelium and the stroma in the proliferative phase of the menstrual cycle, with negligible staining around the vascular endothelium. In contrast, the staining intensified around the blood vessels of the endometrium in the secretory phase. These findings are in contrast to the results of Raju and Lee (27) who showed immunocytochemical localization of renin in the stroma and the glands of some of the sections of proliferative endometrium but no staining in secretory endometrium; the negative reactivity in these sections may relate to loss of antigenicity due to formalin fixation. This is supported by our preliminary results using frozen sections which show that renin immunoreactive protein is present in both proliferative and secretory endometrium (our unpublished data).

The cyclic changes in ANG II-like immunoreactivity imply that this octapeptide may play a dual role in the endometrium: (a) as a controller of the uterine vascular bed and $(b)$ as an angiogenic and mitogenic mediator in the regeneration of the endometrium after endometrial shedding. During the early to mid proliferative phase when the endometrium undergoes rapid cell division, angiotensin-like immunoreactivity was confined to the stroma and the glandular epithelium. The stroma and the glandular epithelium showed typical brown granular cytoplasmic staining while there was no staining around the blood vessels. In addition, in situ hybridization studies revealed that $\mathrm{AT}_{1}$ receptor mRNA was highly expressed both in the glands and stromal cells in proliferative endometrium, while hybridization signal were relatively weak in the stroma of secretory endometrium. 

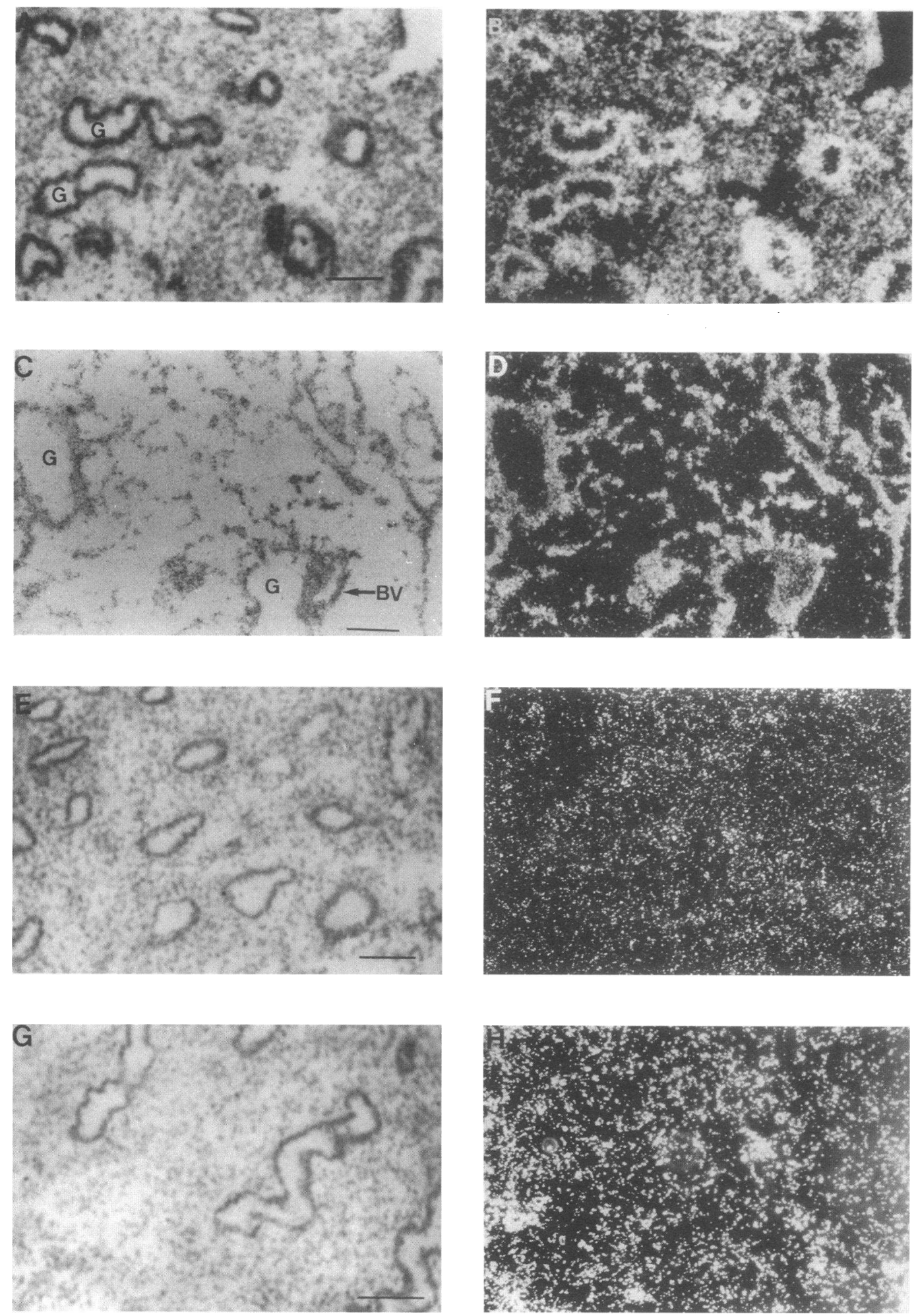

Figure 5. In situ localization of $\mathrm{AT}_{1}$ receptor mRNA expression in human endometrium. Bright-field $(A, C, E$, and $G)$ and dark-field $(B, D, F$, and $H$ ) photomicrographs of sections of endometrium after in situ hybridization with ${ }^{35} \mathrm{~S}$-labeled oligonucleotide directed against $\mathrm{AT}_{1}$ in proliferative endometrium $(A$ and $B)$ and secretory endometrium $(C$ and $D)$. The high level of $\mathrm{AT}_{1}$ mRNA expression is seen around the glandular epithelium $(G)$ and the endometrial blood vessels $(B V) . E$ and $F$ indicate RNAse-treated serial section showing no hybridization while $G$ and $H$ show significant reduction in hybridization signal after incubation of labeled probe along with 100-fold excess of unlabeled probe. Bar, $150 \mu \mathrm{m}$.

As there is rapid capillary growth associated with endometrial regeneration after menstruation, it is possible that ANG II may modulate cell growth and neovascularization directly or through the expression of other growth factors or protooncogenes. ANG II was reported to stimulate basic fibroblast growth factor expression in bovine luteal cells (28) which stimulates 

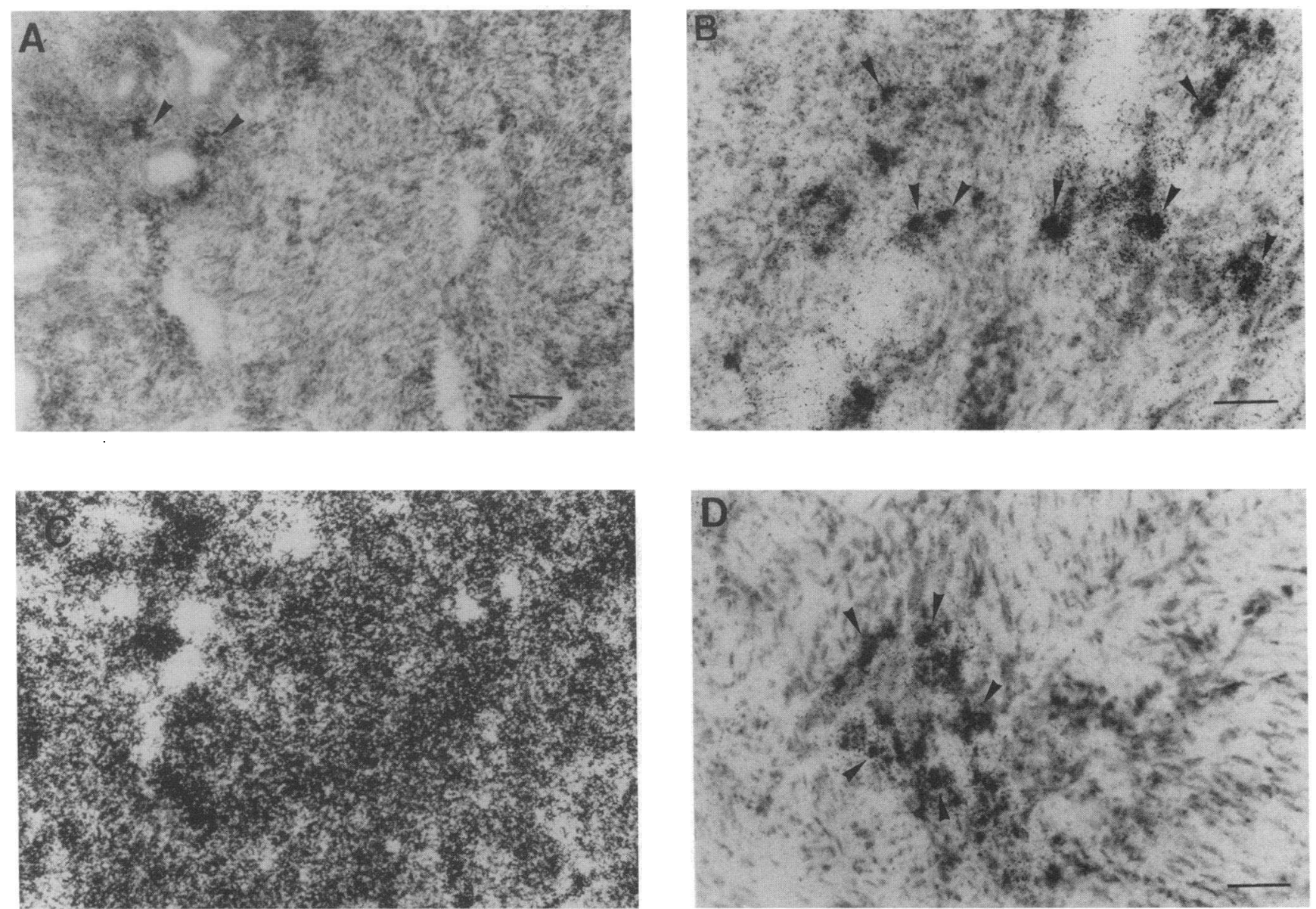

Figure 6. In situ localization of $\mathrm{AT}_{1}$ receptor mRNA expression in myometrium. $A$ shows a bright-field view of an endometrial-myometrial section at the endometrial-myometrial junction hybridized with oligonucleotide directed against $\mathrm{AT}_{1} ; C$ shows a dark-field view of the same section; $B$ and $D$ show bright-field view of myometrial section. Arrows indicate blood vessels at the endometrial-myometrial junction $(A)$ and the intense hybridization of isolated cells $(B$ and $D)$ within the myometrium. Bar, $150 \mu \mathrm{m}$.

endothelial cell proliferation (29). Also, ANG II has been shown to stimulate the expression of platelet-derived growth factor (30) as well as growth-related oncogenes in cultured smooth muscle cells (31). ANG II-stimulated 42-44-kD tyrosine-phosphorylated proteins such as the mitogen-activated protein kinase in rat aortic smooth muscle cells (32) suggest that ANG II may be involved in cell proliferation as this enzyme family has been shown to play a pivotal role in the regulation of cell division $(33,34)$.

As ANG II is a potent vasoconstrictor, the very intense staining seen around the endometrial blood vessels in the late luteal phase suggests its possible role in the initiation of menstruation by the vasoconstriction of the spiral arteriole before menstruation. Although $>60 \%$ of specific $\left[{ }^{125} \mathrm{I}\right]$-ANG II binding was associated with the $\mathrm{AT}_{2}$ receptor, $\sim 20 \%$ was due to $\mathrm{AT}_{1}$ receptor. Using in situ hybridization studies, the expression of $\mathrm{AT}_{1}$ receptor mRNA in secretory endometrium was demonstrated in the endometrial glands and in the endometrial blood vessels. Strong hybridization signal for $\mathrm{AT}_{1}$ receptor mRNA was also seen in and around the blood vessels at the endometrial-myometrial junction in late secretory endometrium, which suggests that ANG II may contribute to the vasoconstriction of the spiral arterioles. A similar result demonstrating binding sites for iodinated endothelins was reported in human uterus (35), however, the effect of endothelins on uterine blood vessels is not known. On the other hand, ANG II was reported to induce a dose-dependent contraction of human uterine artery (36). The apparent lack of autoradiographic sensitivity in detecting $\mathrm{AT}_{1}$ receptor may be due to lack of translation of the $\mathrm{AT}_{1}$ receptor mRNA to receptor protein. More likely, it is due to the relatively low density of $\mathrm{AT}_{1}$ receptors in the endometrium. Some autoradiographic studies have failed to demonstrate ANG II binding to preglomerular vessels in rat, rabbit, and human kidney (37) while others have reported that there is a predominance of $\mathrm{AT}_{1}$ receptors in preglomerular vessels (38).

The function of AT receptor subtypes in the uterus is not yet established and the demonstration of specific sites does not necessarily imply a physiological role. As mentioned earlier, ANG II induced a dose-dependent contraction of human uterine artery (36), however, the study did not look at the receptor subtype involved. The expression of $\mathrm{AT}_{1}$ receptor mRNA in vascular smooth muscle would be consistent with a vasoconstrictor role which has been demonstrated in the feto-placental circulation (39), and in the ovine fetus infusion of ANG II markedly reduces feto-placental perfusion and causes a redistribution of blood flow to the heart and brain at the expense of renal, hepatic, and gut perfusion (40). In women, most of the functional endometrium is shed within $20 \mathrm{~h}$ of the onset of 
menstrual bleeding and hemostasis is achieved by vasoconstriction of the remaining basal arteriolar fragments (3). Although prostaglandin $\mathrm{F}_{2 \alpha}$ and endothelins have been suggested as putative endometrial vasoconstrictor candidates (5), neither pressor agent displays the cyclic changes in peptide or receptor to be a possible candidate for a "dual role peptide" as proposed by this study for the actions of ANG II in human endometrium. The expression of $\mathrm{AT}_{1}$ receptor mRNA around the blood vessels and the intense localization of ANG II-like immunoreactivity in the perivascular stromal cells around the blood vessels in late secretory endometrium supports a role of ANG II in providing the pressor mechanism to initiate menstruation and in the control of bleeding from the basal arteries.

The presence of clusters of cells (possibly inflammatory cells) among the myometrial cells, with substantially higher signal for $\mathrm{AT}_{1}$ receptor mRNA than the surrounding cellular elements, is of some interest. A recent study reported a similar expression of insulin-like growth factor and its receptors in endometrium (41) and suggest that these cells are inflammatory cells, possibly monocytes and macrophages. Although the role of macrophages in uterine tissue has not yet been determined, it is known that cocultures of endometrial stromal cells and macrophages stimulate stromal cell growth under serum-free conditions (41).

In addition to the control of vascular tone, the degree of menstrual bleeding is determined by endometrial regeneration which is essential in the preparation of a receptive endometrium for the implantation of a developing embryo. The factors controlling this regeneration of the endometrium are poorly understood. The $\mathrm{AT}_{2}$ receptors may promote cell growth (16) and are highly expressed in human endometrium. Increasing evidence indicates that estrogen-stimulated endometrial growth is mediated by locally produced growth factors (42). Increase in the intensity of specific [ $\left.{ }^{125} \mathrm{I}\right] \mathrm{AT}$ receptor binding from early and mid proliferative to late proliferative and reaching maximal levels in the early secretory endometrium implies that the AT receptors may be upregulated by estrogen in the first half of the menstrual cycle. The decrease in the specific [ $\left.{ }^{125} \mathrm{I}\right] \mathrm{AT}$ receptor binding in mid and late secretory endometrium from the levels in early secretory endometrium suggests that progesterone may be antagonizing the effects of estrogen. The functional significance of the high levels of specific [ $\left.{ }^{125} \mathrm{I}\right] \mathrm{AT}$ receptor binding during the late proliferative and early secretory endometrium is not known, but may relate to the preparation of endometrium for implantation.

In addition to losartan- and PD123177-sensitive specific [ $\left.{ }^{125} \mathrm{I}\right]$-AT receptors, an additional high-affinity binding site was consistently detected that was insensitive to both losartan and PD 123177 but was displaced with low concentration of unlabeled ANG II. This novel high-affinity AT recognition site represented $\sim 16 \%$ of specific total binding but its potential function and pharmacology remain to be elucidated. It was recently proposed that the angiogenic action of ANG II may be mediated via an unknown AT receptor subtype (10). This non-AT $1 /$ non$\mathrm{AT}_{2}$ binding site in the endometrium may relate to the fact that the endometrium undergoes extensive cyclic angiogenesis and warrants further investigation.

\section{Acknowledgments}

We are grateful to Dr. G. F. Steinfels (DuPont Merck Pharmaceuticals, Wilmington, DE) for the gifts of losartan and PD123177. We would like to thank the Consultants, Theatre, and Pathology staff of the Birmingham Maternity Hospital for their help with this study.

This work was supported by grants from the Well Being project grant A2/94 and Mary Crosse. M. Shams is a post-doctoral research fellow funded by Well Being project grant A2/93.

\section{References}

1. Cameron, I. T. 1992. Medical management of menorrhagia. Curr. Obstet. Gynecol. 2:136-140.

2. Markee, J. E. 1940. Menstruation in intraocular endometrial transplants in the rhesus monkey. Contrib. Embryol. Carnegie Inst. 28:219-308.

3. Christiaens, G. C. M. L., J. J. Sixma, and A. A. Haspels. 1980. Morphology of haemostasis in menstrual endometrium. Br. J. Obstet. Gynaecol. 87:425-439. 4. Ludwig, H., H. Metzger, and M. Frauli. 1990. Endometrium: tissue remodelling and regeneration. In Contraception and Mechanisms of Endometrial Bleeding. C. d'Arcangues, I. S. Fraser, J. R. Newton, and V. Odlind, editors. Cambridge University Press, Cambridge, United Kingdom. 441-466.

5. Maigaard, S., A. Forman, and K.-E. Andersson. 1985. Different responses to prostaglandin $\mathrm{F}_{2 \alpha}$ and $\mathrm{E}_{2}$ in human extra- and intramyometrial arteries. Prostaglandins. 30:599-607.

6. Cameron, I. T., and A. P. Davenport. 1992. Endothelins in reproduction. Rep. Med. Rev. 1:99-113.

7. O'Reilly, G. D. S. Charnock-Jones, A. T. Davenport, I. T. Cameron, and S. K. Smith. 1992. Presence of messenger ribonucleic acid for endothelin-1, endothelin-2, and endothelin- 3 in human endometrium and a change in the ratio of ET-A and ET-B receptor subtype across the menstrual cycle. J. Clin. Endocrinol. \& Metab. 75:1545-1549.

8. Le Noble, J. L. M. L, J. W. M. Hekking, H. W. M.Van Straaten, D. W. Slaaf, and H. A. J. Struyker-Boudier. 1991. Angiotensin II stimulates angiogenesis in the chorio-allantoic membrane of the chock embryo. Eur. J. Pharmacol. 195:305-306.

9. Fernandez, L. A., J. Twickler, and A. Mead. 1985. Neovascularization produced by angiotensin II. J. Lab. Clin. Med. 105:141-145.

10. Le Noble, F. A. C., N. H. J. S. Schreurs, H. W. M. Van Straaten, D. W. Slaaf, J. F. M. Smits, H. Rogg, and A. J. Struijker-Boudier. 1993. Evidence for a novel angiotensin II receptor involved in angiogenesis in chick embryo chorioallantoic membrane. Am. J. Physiol. 264:R460-R465.

11. Baker, K. M., and J. F. Aceto. 1990. Angiotensin II stimulation of protein synthesis and cell growth in chick heart cells. Am. J. Physiol. 259:H610-H618.

12. Wong, P. C., S. D. Hart, A. M. Zaspel, A. T. Chiu, R. J. Ardecky, R. D. Smith, and P. B. M. W. M. Timmermans. 1990. Functional studies of nonpeptide angiotensin II receptor subtype-specific ligands: Dup753 (AII-1) and PD123177 (AII-2). J. Pharmacol. Exp. Ther. 255:584-592.

13. Murphy, T. J., R. W. Alexander, K. K. Griendling, M. S. Runge, and K. E. Bernstein. 1991. Isolation of a cDNA encoding the vascular type-1 angiotensin II receptor. Nature (Lond.). 351:233-236.

14. Mukoyama, M., M. Nakajima, M. Horiuchi, H. Sasamura, R. E. Pratt, and V. J. Dzau. 1993. Expression cloning of type-2 angiotensin II receptor reveals a unique class of 7-transmembrane receptors. J. Biol. Chem. 268:2539-2542.

15. Wong, P. C., A. T. Chiu, J. V. Duncia, W. F. Herblin, R. D. Smith, and P. B. M. W. M. Timmermans. 1992. Angiotensin II receptor antagonists and receptor subtypes. Trends Endocrinol. Metab. 3:211-217.

16. Bottari, S. P., I. N. King, S. Reichlin, I. Dahlstroem, N. Lydon, and M. de Gasparo. 1992. The angiotensin AT2 receptor stimulates protein tyrosin phosphatase activity and mediates inhibition of particulate guanylate cyclase. Biochem. Biophys. Res. Commun. 183:206-211.

17. Hendrickson, M. R., and R. L. Kempson. 1980. The normal endometrium: the base line. In Surgical Pathology of Uterus Corpus. M. R. Hendrickson and R. L. Kempson, editors. W. B. Saunders, Philadelphia. 36-98.

18. Noyes, R. W., A. T. Hertig, and J. Rock. 1950. Dating the endometrial biopsy. Fertil. Steril. 1:3-25.

19. Li, X. F., J. Gregory, and A. Ahmed. 1994. Immunolocalization of vascular endothelial growth factor in human endometrium. Growth Factors. 11:277-282.

20. Iwai, N., S. Y. Chaki, F. Konishi, S. Bardhan, C. Tibbetts, K. Sasaki, M. Hasegawa, Y. Matsuda, and T. Inagami. 1991. Rat angiotensin II receptor cDNA sequence and regulation of the gene expression. Biochem. Biophys. Res. Commun. 177:299-304.

21. Bergsma, D. J., C. Ellis, C. Kumar, P. R. Nuthulaganti, H. Kersten, N. Elshourbagy, E. Griffin, J. M. Stadel, and N. Aiyar. 1992. Cloning and characterization of a human angiotensin II type I receptor. Biochem. Biophys. Res. Commun. 183:989-995.

22. Shams, M., and A. Ahmed. 1994. Localization of mRNA for basic fibroblast growth factor in human placenta. Growth Factors. 11:105-111.

23. Palumbo, A. C., A. Jones, M. L. Lightman, M. L. Carcangiu, A. H De Cherney, and F. Naftolin. 1989. Immunohistochemical localization of renin and angiotensin II in human ovaries. Am. J. Obstet. Gynecol. 160:8-14.

24. Johnson, I. R. 1980. Renin substrate, active and acid activatable renin 
concentrations in human plasma and endometrium during the normal menstrual cycles. Br. J. Obstet. Gynecol. 87:875-882.

25. Campbell, D. J. 1987. Circulating and tissue angiotensin systems. J. Clin. Invest. 79:1-6.

26. Shah, S. M., K. Higuchi, T. Inagami, and K. G. Osteen. 1991. Effect of progesterone on renin secretion in endometrial stromal, chorionic trophoblast, and mesenchymal monolayer cultures. Am. J. Obstet. Gynecol. 164:1145-1150.

27. Raju, G. C., and Y. S. Lee. 1989. Immunohistochemical demonstration of renin in the endometrium. Ann. Acad. Med. 18:345-347.

28. Stirling, D., R. R. Magness, R. Stow, M. R. Waterman, and E. R. Simpson. 1990. Angiotensin II inhibits leutenising hormone-stimulated cholesterol size chain cleavage expression and stimulates basic fibroblast growth factor expression in bovine leuteal cells in primary culture. J. Biol. Chem. 265:5-81.

29. Ahmed, A., R. Plevin, M. Shaobi, S. A. Fountain, R. A. Ferriani, and S. K. Smith. 1994. Basic FGF activates phospholipase D in endothelial cells in the absence of inositol-lipid hydrolysis. Am. J. Physiol. 266:C206-C212.

30. Bobik, A., S. Grinpukel, P. J. Little, A. Grooms, and G. Jackman. 1990. Angiotensin II and noradrenaline increase PDGF-BB receptors and potentiate PDGF-BB stimulated DNA synthesis in vascular smooth muscle. Biochem. Biophys. Res. Commun. 166:580-588.

31. Taubman, M. B., B. C. Berk, S. Izumo, T. Tsuda, R. W. Alexander, and R. Nadal-Ginard. 1989. Angiotensin II induces c-fos mRNA in aortic smooth muscle. J. Biol. Chem. 264:526-530.

32. Molloy, C. J., D. S. Taylor, and H. Weber. 1993. Angiotensin II stimulation of rapid protein tyrosine phosphorylation and protein kinase activation in rat aortic smooth muscle cells. J. Biol. Chem. 268:7338-7345.

33. Pulvener, B. J., J. M. Kymakis, J. Avruch, E. Nikolakaki, and J. R. Woodgeti. 1991. Phosphorylation of c-jun by MAP kinase. Nature (Lond.). 353:670-674.
34. Wood, K. W., C. Sarnecki, T. M. Roberts, and J. Blenis. 1992. Ras mediates nerve growth factor receptor modulation of three signal-transducing protein kinases: MAP kinase, Raf-1 and RSK. Cell. 68:1041-1050.

35. Davenport, P. A., I. T. Cameron, S. K. Smith, and J. M. Brown. 1991. Binding sites for iodinated endothelin-1, endothelin-2 and endothelin-3 demonstrated on human uterine glandular epithelial cells by quantitative high-resolution autoradiography. J. Endocrinol. 129:149-154.

36. Poulsen, H., N. Sjoberg, M. Stjernquist, and E. Zia. 1994. Atrial natriuretic peptide antagonizes the contractile effect of angiotensin II in the human uterine artery. Hum. Reprod. (Oxf.). 9:1939-1943.

37. Grone, H. J., M. Simon, and E. Fuchs. 1992. Autoradiographic characterization of angiotensin receptor subtypes in fetal and adult human kidney. Am. J. Physiol. 262:F326-F331.

38. De Leon, H., and R. Garcia. 1993. Angiotensin II receptor subtypes in rat renal preglomerular vessels. Receptor. 2:253-260.

39. Adamson, S. L., R. J. Morrow, S. B. Bull, and B. L. Lurigille. 1989. Vasomotor responses of the umbilical circulation in fetal sheep. Am. J. Physiol. 256:R1056-R1062.

40. Clark, K. G., G. I. Irion, and C. E. Mack. 1990. Differential responses of uterine and umbilical vasculatures to angiotensin II and norepinephrine. Am. J. Physiol. 259:H197-H203.

41. Tang, X.-M., M. J. Rossi, B. J. Masterson, and N. Chegini. 1994. Insulinlike growth factor I (IGF-I), IGF-I receptors and IGF binding proteins 1-4 in human uterine tissue: tissue localization and IGF-I action in endometrial stromal and myometrial smooth muscle cells in vitro. Biol. Reprod. 50:1113-1125.

42. Nelson, K. G., T. Takashi, N. L. Bossert, D. K. Walmer, and J. A. Mclachlan. 1991. Epidermal growth factor replaces estrogen in the stimulation of female genital tract growth and differentiation. Proc. Natl. Acad. Sci. USA. 88:2125 . 